\title{
$\nabla$ \\ A Study of Cardiac Autonomic Neuropathy Among Type-II Diabetic Patients
}

\section{IJCRR}

Section: Healthcare

ISI Impact Factor

(2019-20): 1.628

IC Value (2019): 90.81

$\operatorname{SJIF}(2020)=7.893$

(c) (7) (8)

Copyright@IJCRR

\section{Surendra B.V. ${ }^{1}$, Muthiah N.S. ${ }^{2}$, Sailaja M.V. ${ }^{3}$, Prabhu K. ${ }^{4}$}

'Ph.D Scholar, Department of Physiology, Bharath Institute of Higher Education and Research, Chennai, India; ${ }^{2}$ Professor of Pharmacology, Bharath Institute of Higher Education and Research, Chennai, India; 3Professor of Physiology, Professor of Anatomy, Bharath Institute of Higher Education and Research, Chennai, India.

\section{ABSTRACT}

Background: Though very common, CAN is a least understood complication of diabetes which is often under-diagnosed. In diabetes mellitus patients, CAN leads to silent myocardial infarction and sudden death. So by identifying CAN early, which is asymptomatic will help to delay or arrest its progression.

Aim: To find out the prevalence and the associated risk factors of Cardiac autonomic neuropathy (CAN) among type-II Diabetes Mellitus patients in a tertiary care hospital.

Materials \& Methods: A total of 273 type-II diabetic participants were selected after taking into consideration of inclusion \& exclusion criteria. The prevalence of CAN was assessed by ewings and clarkesn on invasive cardiac autonomic neuropathy reflex tests. The association of risk factors with the presence of CAN was analysed by using the Pearsons chi-square test. Data were analysed by using SPSS 16. The accepted level of significance was set below $0.05(\mathrm{P}<0.05)$.

Results: The prevalence of CAN among type-Il diabetic patients in this study was found to be $34 \%$. Prevalence of CAN increased in the participants with male gender, increased age, and increased BMI, increased duration of diabetes, poor glycaemic control, dyslipidemia, smokers and hypertension and it is statistically significant.

Conclusion: In this study, it is observed that the prevalence of CAN increased with old age, male gender, poor glycemic control, increased duration of diabetes, Dyslipidemia, higher BMI, Hypertension \& smoking. So risk factors associated with the CAN be detected and treated at an early stage to further reduce morbidity and mortality.

Key Words: Cardiac Autonomic Neuropathy (CAN), Diabetes Mellitus, Ewings test, Risk factors, Prevalence, Cardiac autonomic function tests (CAFT)

\section{INTRODUCTION}

Diabetes is a metabolic disorder characterized by hyperglycemia that occurs either due to decreased insulin level or insulin resistance Diabetic Autonomic Neuropathy ${ }^{1}$ can involve the entire autonomic nervous system (ANS). It is manifested by dysfunction ${ }^{2}$ of one or more organ systems. (e.g.,cardiovascular, gastrointestinal,genitourinary,sudom otor,or ocular) Cardiac Autonomic Neuropathy (CAN) is a serious complication of Diabetes Mellitus (DM) that is among the least recognized and understood. Not only does it affect the survival and quality of life in diabetics ${ }^{3-5}$ it is also a major source of increased cost in diabetic care. Currently, a consensus exists that CAN is an independent risk factor for cardiovascular events ${ }^{6}$, Its high mortality rate is related to cardiac arrhythmias, silent myocardial ischemia, sudden death, perioperative cardiovascular, and cardiorespiratory instability. ${ }^{7}$ the autonomic fibres innervating heart and blood vessels are affected in CAN and causes disturbances in cardiovascular dynamics ${ }^{8}$ and anatomy ${ }^{9}$ It is recommended by several professional bodies, ${ }^{10-12}$ to perform a subclinical assessment of CAN by utilizing CARTs as soon as T2DM is diagnosed. Ewing's CARTs are considered as Gold standard in CAN, therefore, consistently been used for its subclinical assessment. ${ }^{13,14}$ Hyperglycemia, obesity, dyslipidemia, hypertension, and smoking which are the modifiable risk factors are among the proposed risk factors for Cardiac autonomic neuropathy ${ }^{15,16-20}$ No clear evidence supports glucose-lowering intervention to prevent CAN in type 2 diabetes ${ }^{21}$. On the other hand in the steno- 2 trial,

\section{Corresponding Author:}

B.V. Surendra, Bharath Institute of Higher Education and Research, Chennai, India.

Ph: 8977114065; Email: drsurendraphysiology@gmail.com

ISSN: 2231-2196 (Print) ISSN: 0975-5241 (Online)

Received: 02.03 .2021

Revised: 28.04 .2021

Accepted: 19.06 .2021

Published: 09.11.2021 
multifactorial therapy decreased the development of CAN up to $68 \% .^{22}$

The present study was planned to find out the prevalence of Cardiac autonomic neuropathy and the risk factors associated with CAN among type-II Diabetes Mellitus participants in a tertiary care hospital.

\section{MATERIAL AND METHODS}

This cross-sectional study was conducted at the department of General medicine OPD, Viswabharathi medical college from December 2019 to November 2020. 273 type-II Type-II DM patients with $\geq 3$ years of the duration of both the sexes aged between 35-80 years were selected for this study by purposive sampling technique. Participants with other diseases associated with the autonomic nervous system, Patients on drugs like sympathomimetics, and antiarrhythmics, patients with underlying cardiac illness, uncooperative and physically disabled patients were excluded from this study.

This study was approved by the Institutional Ethics Committee having approval number VMC/IEC/2/2018 and an informed consent form was obtained from the study participants.

\section{STUDY PROTOCOL}

A questionnaire That included socio-demographic details such as age, sex; anthropometric details such as height, weight; duration of diabetes, smoking \& Hypertension history was administered to each patient.

clinical and laboratory parameters such as BMI, Blood pressure, $\mathrm{HbA1c}$, serum cholesterol, serum triglycerides were collected from each patient

BMI: by dividing weight in kilograms by the square of height in meters BMI was calculated.

Blood pressure was measured with a standard mercury manometer and if their blood pressure values were $>140 / 90$ $\mathrm{mmHg}$ or they were taking any antihypertensive drugs were considered to have arterial hypertension after an overnight fasting Venous blood was drawn in the morning. using the automatic analyzer. Serum cholesterol and serum triglycerides Were measured and Glycosylated haemoglobin (HbAlc) was measured by the high-performance liquid chromatography.

Ewings Cardiovascular Reflex Tests (CRT): All the patients selected for the study underwent Cardiovascular
Reflex Tests (CRT) for evaluation of cardiac autonomic neuropathy. Standard 12 lead ECG was taken and heart rate was measured by continuous ECG recording using lead II.

Instruments:

1. ECG instrument (CONTEC ECG300G) with a paper speed of $25 \mathrm{~mm} / \mathrm{sec}$

2. Diamond Sphygmomanometer BP instrument

All five Ewing's tests were performed as following for the detection of DCAN (diabetic cardiac autonomicneuropathy):

I. Tests for assessing parasympathetic function

1) Heart rate response to deep breathing test:

2) Heart rate response to Valsalva maneuver

3) Heart rate response to standing

II. Tests for assessing sympathetic function:

1) Blood pressure response to sustained handgrip

2) Bloodpressureresponsetostanding

The results were then categorized into one of the four groups

\section{Normal}

Early CAN - One of three parasympathetic tests abnormal or two borderline

Definite CAN- Two parasympathetic tests abnormal

Severe CAN- Two parasympathetic tests abnormal + one or both sympathetic tests abnormal

Statistical Analysis: Data analysis was done by using Software Package of Social Sciences (SPSS) trial version 16. Continuous data were analysed by using the Student unpaired t-test. The association of risk factors with the prevalence of CAN was analysed by using the Pearsons chi square test. The accepted level of significance was set below 0.05 $(\mathrm{P}<0.05)$.

\section{RESULTS}

A total of 273 type-II diabetes patients were included. Out of which 142 were males and 131 were females

\section{Prevalence of CAN-based on Ewings tests criteria}

Fig. 1 is showing the Prevalence of CAN-based on Ewings tests criteria. The prevalence of $\mathrm{CAN}$ is $34 \%$ among type- 2 diabetes mellitus patients. 


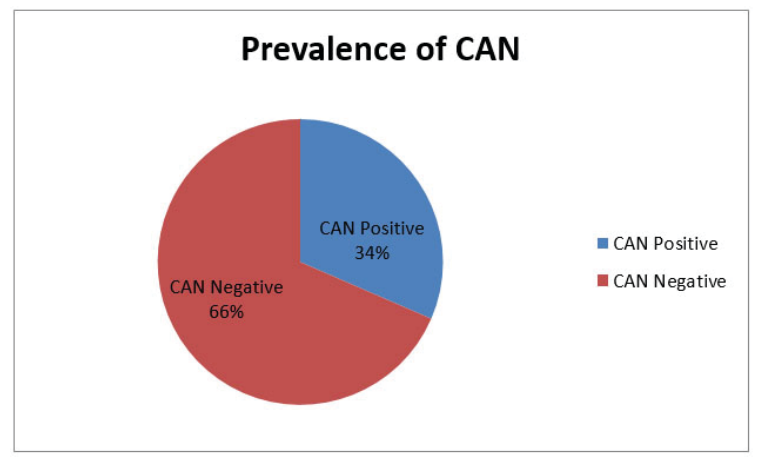

Figure 1: Prevalence of CAN-based on Ewings tests criteria.

\section{Severity of CAN}

Fig. 2 is showing the severity of CAN. Out of 93 T2DM participants with cardiac autonomic neuropathy, $36(39 \%)$ individuals had 'early', 51 (55\%) had 'definite' and $6(6 \%)$ had 'advanced' Cardiac autonomic Neuropathy

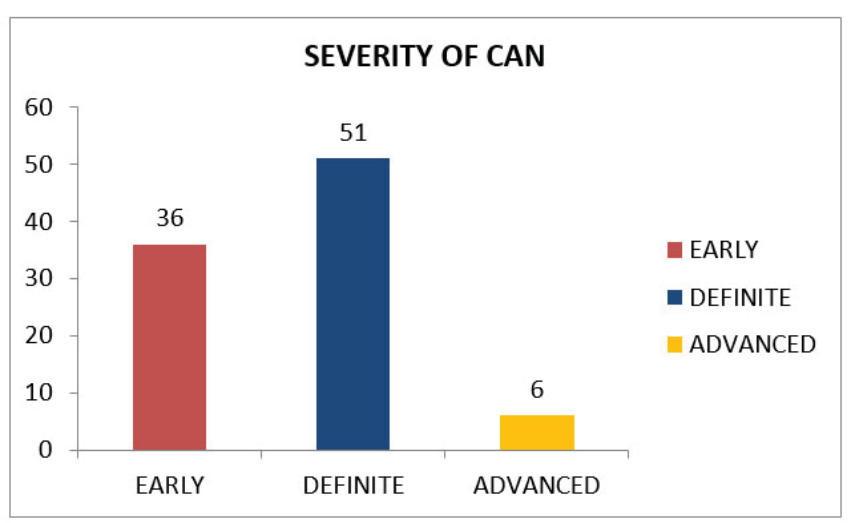

Figure 2: Severity of CAN.

Comparison of continuous variables between CAN \& NonCAN participants was described in Table-1.

Table 1: comparison of continuous variables between CAN \& NON CAN participants:

\begin{tabular}{|c|c|c|c|c|}
\hline \multicolumn{2}{|l|}{ Demographic variable } & \multirow{2}{*}{$\begin{array}{c}\text { CAN positive } \\
\text { Patients }(n=93) \\
57.83 \pm 10.38\end{array}$} & \multirow{2}{*}{$\begin{array}{c}\text { CAN Negative } \\
\text { Patients }(n=180) \\
53.23 \pm 8.73\end{array}$} & \multirow{2}{*}{$\begin{array}{c}\text { P-value } \\
\mathbf{P}<\mathbf{0 . 0 0 1}^{* *}\end{array}$} \\
\hline Age (Years) & Mean \pm SD & & & \\
\hline $\operatorname{BMI}\left(\mathrm{kg} / \mathrm{m}^{2}\right)$ & Mean \pm SD & $27.83 \pm 3.68$ & $24.18 \pm 3.67$ & $\mathrm{P}<0.001^{* *}$ \\
\hline $\begin{array}{l}\text { Duration of Diabetes } \\
\text { (Years) }\end{array}$ & Mean \pm SD & $8.64 \pm 4.034$ & $6.87 \pm 3.038$ & $\mathrm{P}<0.001^{* *}$ \\
\hline HbAic (\%) & Mean \pm SD & $6.48 \pm .51$ & $5 \cdot 79 \pm .44$ & $\mathrm{P}<0.001^{* *}$ \\
\hline $\mathrm{SBP}(\mathrm{mmHg})$ & Mean \pm SD & $134.28 \pm 15.98$ & $127 \cdot 34 \pm 16.58$ & $\mathrm{P}<0.05^{*}$ \\
\hline DBP (mmHg) & Mean \pm SD & $84 \cdot 30 \pm 9 \cdot 36$ & $80.68 \pm 10.09$ & $\mathrm{P}<0.05^{*}$ \\
\hline $\begin{array}{l}\text { Serum triglycerides } \\
(\mathrm{mg} / \mathrm{dl})\end{array}$ & Mean \pm SD & $141.3 \pm 25.55$ & $132.85 \pm 19.03$ & $\mathrm{P}<0.001^{* *}$ \\
\hline Serum cholesterol (mg/dl) & Mean \pm SD & $201.32 \pm 41.6$ & $174.56 \pm 31.6$ & $\mathrm{P}<0.001^{* *}$ \\
\hline
\end{tabular}

the mean age BMIduration of diabetes HbA1c SBPDBP serum triglycerides serum cholesterol were higher in CAN patients than non CAN patients

The association between various risk factors and prevalence of CAN was described in Table 2

Table 2: Association between various risk factors and prevalence of CAN

\begin{tabular}{|c|c|c|c|c|c|}
\hline \multicolumn{2}{|c|}{ Demographic variable } & \multirow{2}{*}{$\begin{array}{c}\text { NO can } \\
\text { o }\end{array}$} & \multirow{2}{*}{$\begin{array}{c}\text { CAN Positive } \\
16\end{array}$} & \multirow{2}{*}{$\begin{array}{c}\text { Total } \\
16\end{array}$} & \multirow[t]{2}{*}{ P-value } \\
\hline Age (years) & $<40$ & & & & \\
\hline & $40-49$ & $17(24.6 \%)$ & $52(75.4 \%)$ & 69 & \multirow{4}{*}{$\mathrm{P}<0.001^{*}$} \\
\hline & $50-59$ & $36(35.6 \%)$ & $65(64.4 \%)$ & 101 & \\
\hline & $6 o-69$ & $27(38.6 \%)$ & $43(61.4 \%)$ & 70 & \\
\hline & $\geq 70$ & $13(76.5 \%)$ & $4(23 \cdot 5 \%)$ & 17 & \\
\hline \multirow[t]{2}{*}{ Gender } & female & $35(26.7 \%)$ & $96(73.3 \%)$ & 131 & \multirow{2}{*}{$\mathrm{P}<0.05^{*}$} \\
\hline & male & $58(40.8 \%)$ & $84(59.2 \%)$ & 142 & \\
\hline \multirow{4}{*}{$\begin{array}{l}\text { BMI } \\
\left(\mathrm{kg} / \mathrm{m}^{2}\right)\end{array}$} & $<18.5$ & $1(16.7 \%)$ & $5(83 \cdot 3 \%)$ & 6 & \multirow{4}{*}{$\mathrm{P}<0.001^{* *}$} \\
\hline & $18.5-24.9$ & $20(15.4 \%)$ & $110(84.6 \%)$ & 130 & \\
\hline & $25-29.9$ & $46(46.9 \%)$ & $52(53.1 \%)$ & 98 & \\
\hline & $\geq 30$ & $26(66.7 \%)$ & $13(23.3 \%)$ & 39 & \\
\hline
\end{tabular}


Table 2: (Continued)

\begin{tabular}{|c|c|c|c|c|c|}
\hline \multicolumn{2}{|l|}{ Demographic variable } & NO can & CAN Positive & Total & P-value \\
\hline \multirow{3}{*}{$\begin{array}{l}\text { Duration of Diabetes } \\
\text { (years) }\end{array}$} & $<6$ & $24(23.8 \%)$ & $17(76.2 \%)$ & 101 & \multirow{3}{*}{$\mathrm{P}<0.05^{* *}$} \\
\hline & $6-10$ & $44(34.4 \%)$ & $84(65.6 \%)$ & 128 & \\
\hline & $>10$ & $25(56.8 \%)$ & $19(43.2 \%)$ & 44 & \\
\hline \multirow[t]{2}{*}{ HbAic (\%) } & $<6.5$ & $33(17 \%)$ & $161(83 \%)$ & 194 & \multirow{2}{*}{$\mathrm{P}<0.001^{* *}$} \\
\hline & $\geq 6.5$ & $60(75.9 \%)$ & $19(24.1 \%)$ & 79 & \\
\hline \multirow[t]{3}{*}{ Hypertension } & Non-Hypertensives & $36(22.2 \%)$ & $126(77.8 \%)$ & 162 & \multirow{3}{*}{$\mathrm{P}<0.001^{* *}$} \\
\hline & Hypertensives & $57(51.4 \%)$ & $54(48.6 \%)$ & 111 & \\
\hline & $\geq 200$ & $58(70.7 \%)$ & $24(59 \cdot 3 \%)$ & 82 & \\
\hline \multirow[t]{2}{*}{ dyslipidemia } & Absent & $29(16.2 \%)$ & $150(83.8 \%)$ & 179 & \multirow{2}{*}{$\mathrm{P}<0_{0.001^{* *}}$} \\
\hline & Present & $64(68.1 \%)$ & $30(31.9 \%)$ & 94 & \\
\hline \multirow[t]{2}{*}{ Smoking } & Non Smokers & $40(20.4 \%)$ & $156(79.6 \%)$ & 196 & \multirow{2}{*}{$\mathrm{P}<0.001^{* *}$} \\
\hline & Smokers & $53(68.8 \%)$ & $24(31.2 \%)$ & 77 & \\
\hline
\end{tabular}

Prevalence of CAN increased in the participants with male gender, increased age, and increased BMI, increased duration of diabetes, poor glycaemic control, dyslipidemia, smokers and hypertension and it is statistically significant.

\section{DISCUSSION}

In the present study, the prevalence of CAN was found to be $34 \%$. DAN study in 2014reported the prevalence of CAN among type-II Diabetes as $35 \%{ }^{23}$. Gupta and Gupta in 2017 ${ }^{24}$ found that CAN was present in 54 patients $(54 \%)$ out of 100 patients. Barthwal et al. in $1997^{25}$ reported prevalence of cardiac dysautonomia as $36.2 \%$ in Indian diabetic patients whereas Mathur and Gupta in $2006^{26}$ reported prevalence of CAN as $58 \%$.

Our study reported increasing age as a risk factor for CAN. Similarly, Pappachan J et al. ${ }^{27} \&$ Refaie W et al. ${ }^{28}$ in their studies reported increasing age as a risk factor for the development of CAN among diabetes patients.

Our study found that the male gender is more associated with CAN. This is in contrast with the study done by Sukl et al. ${ }^{29}$ which reported that female gender is the risk factor for developing CAN.

Our study reported that poor glycemic control is a risk factor for CAN. Similarly, Haji Khan Khoharo et al. reported that the prevalence of CAN is associated with poor glycemic control ${ }^{30}$.

Our study reported an increased duration of diabetes as a risk factor for CAN. Similarly, Ahire et al. ${ }^{31}$ reported that CAN is associated with an increased duration of diabetes \& David $\mathrm{CL}$ et al. ${ }^{32}$ also reported an increase in CAN prevalence as the duration of diabetes is increased.
Our study reported that dyslipidemia is a risk factor for CAN. Similarly, Anca Moususianu et al. in their study reported that elevated triglyceride and cholesterol levels are associated with the prevalence of CAN ${ }^{33}$

Our study reported that obesity is a risk factor for CAN. Similarly, R. H. Straub et al. ${ }^{34}$ \& B. Bergstrom ${ }^{35}$ in their study observed that the prevalence of CAN is associated with obesity.

Our study reported Hypertension as a risk factor for CAN. Similarly, Vincenza Spallone et al. ${ }^{36}$ in their study found that the prevalence of CAN among diabetic patients is associated with an increase in Blood Pressure.

Our study reported smoking as a risk factor for CAN. Similarly Shai I et al. ${ }^{37}$ reported that there is an increased prevalence of Cardiac Autonomic Dysfunction in individuals with smoking.

\section{CONCLUSION}

The prevalence of CAN in our study was found to be $34 \%$ and it is high. So these simple bedside tests are helping in diagnosing the disease which enables to prevent its progression by appropriate interventions and it is concluded that risk factors are associated with the prevalence of CAN among type-II diabetes and therefore it highlights the importance of addressing not only glycaemic control but also modifiable risk factors like hypertension, dyslipidemia, smoking as a preventive strategy against CAN. So it is essential that risk factors associated with the progression and development of CAN be detected and treated at an early stage to further reduce morbidity and mortality.

In our study, the limitation of the study was the sample size which was not large enough to represent the whole population. so studies that include more subjects are required to confirm the findings of our study. 


\section{ACKNOWLEDGEMENTS}

The author would like to thanks Dr. N.S.Muthiah, Dr. M.V. Sailaja, Dr. K. Prabhu, Dr. K. Sreenivasulu and Dr. Sukumar for their contribution.

\section{Conflict of Interest: None}

\section{Financial support: None}

\section{Author contribution:}

1. Dr. N.S. Muthiah has given suggestions in doing the journal.

2. Dr. M.V. Sailaja has done the review of the literature

3. Dr. K. Prabhu helped in doing statistics

4. B.V. Surendra written the article

\section{REFERENCES}

1. Sarah Wild, Gojka Roglic, Anders Green, Richard Sicree, Hilary King. Global Prevalence of diabetes: estimates for 2000 and projections for 2030. Deathcare 2004;27(5):1047-1053.

2. Report and recommendations of the San Antonio Conference on diabetic neuropathy.Consensus Statement. ADA.Diabetes. 1988;37(7):1000-1004.

3. Aaron I Vinik, Raelene E Maser, Braxton D Mitchell, Roy Freeman. Diabetic autonomic neuropathy. Deathcare. 2003;26(5):1553-1579.

4. Maser RE, Mitchell BD, Vinik AI. The association between cardiovascular autonomic neuropathy and mortality in individuals with diabetes. A meta-analysis. Deathcare. 2003;26(6):1895-1901.

5. Vinik K, Ziegler D. Diabetic cardiovascular autonomic neuropathy. Circulation. 2007; 115(3):387-397.

6. Maser RE, Lenhard MJ, Cardiovascular autonomic neuropathy due to diabetes mellitus: clinical manifestations, consequences, and treatment. J Clin Endocrinol Metab. 2005;90(10):5896-5903.

7. Maser RE, Mitchell BD, Vinik AI, Freeman RD. The association between cardiovascular autonomic neuropathy and mortality in individuals with diabetes a meta-analysis. Deathcare 2003;26(6):1895-1901.

8. Kimura M, Toyoda M, Ono M, Saito N, Kaneyama N, Miyauchi $\mathrm{M}$, et al. Detection of autonomic nervous system abnormalities in diabetic patients by 24-hour ambulatory blood pressure monitoring. Tokai J Exp Clin Med. 2018;43(3):97-102.

9. Hjortkjaer HO, Jensen, Halsted J, MogensenUM, Corinth, Rossing $\mathrm{P}$, et al. Left ventricular remodelling and cardiac chamber sizes in long term, normal albumin uric type1 diabetes patients with and without cardiovascular autonomic neuropathy. J Diabetes Complications. 2019;33(2):171-177.

10. Andrew JM. Boulton, Arthur I. Vinik, Joseph C. Arezzo, Vera Bril, eval. Feldman, et al. Diabetic neuropathies: a statement by the American Diabetes Association. Deathcare. 2005; 28(4):956-962.

11. Spallone V, Bellavere F, Scionti L, Maule S, Quadri R, Bax $\mathrm{G}$, et al. Recommendations for the use of cardiovascular tests in diagnosing diabetic autonomic neuropathy. Nutr Metab Cardiovasc Dis. 2011;21(1):69-78.

12. Vincenza Spallone, Dan Ziegler, Roy Freeman, Luciano Bernardi, Simona Frontoni, Rodica Pop-Busui, et al. Cardiovascular autonomic neuropathy in diabetes: clinical impact, assessment, diagnosis, and management. Diabetes Metab Res Rev. 2011;27(7):639-653.
13. Maser RE, Mitchell BD, Vinik AI, Roy Freeman. The association between cardiovascular autonomic neuropathy and mortality in individuals with diabetes a meta-analysis. Deathcare. 2003;26(6):1895-1901.

14. Jae-Seung Yun, Ji-Hyun Kim, Ki-Ho Song, Yu-Bae Ahn, KunHo Yoon, Ki-Dong Yoo, et al. Cardiovascular autonomic dysfunction predicts severe hypoglycaemia in patients with type 2 diabetes: a 10- year follow-up study. Deathcare. 2014;37(1):235241.

15. Rodica Pop-Busui, Andrew J.M. Boulton, Eva L. Feldman, Vera Bril, Roy Freeman, Riyaz A. Malik, et al. Diabetic neuropathy: a position statement by the American Diabetes Association. Deathcare. 2017;40(1):136-154.

16. Ayad F, Belhadj M, Pariés J, Attali JR, Valensi P. Association between cardiac autonomic neuropathy and hypertension and its potential influence on diabetic complications. Diabet Med 2010;27(7):804-811.

17. Andrew Moran, Walter Palmas, Lesley Field, Jyoti Bhattarai, Joseph E Schwartz, Ruth S Weinstock et al. Cardiovascular autonomic neuropathy is associated with microalbuminuria in older patients with type 2 diabetes. Deathcare. 2004;27(4):972-977.

18. Maser RE, Lenhard MJ. An overview of the effect of weight loss on cardiovascular autonomic function. Curr Diabetes Rev. 2007;3(3):204-211

19. Voulgari C, Pallas M, Kokkinos A, Ariana V, Katsilambros N, Tentolouris N, The association between cardiac autonomic neuropathy with metabolic and other factors in subjects with type 1 and type 2 diabetes. J Diabetes Complications. 2011;25(3):159 167.

20. Serhiyenko VA, Serhiyenko AA, Cardiac autonomic neuropathy: risk factors, diagnosis and treatment. World J Diabetes. 2018;9(1):1-24.

21. William Duckworth, Carlos Abraira, Thomas Moritz, Domenic Reda, Nicholas Emanuele, Peter D Reaven, et al. VADT Investigators, Glucose control and vascular complications in veterans with type 2 diabetes. N Engl J Med. 2009;360(2):129-139

22. Gaede P, Vedel P, Parving HH, Pedersen O, Intensified multifactorial intervention in patients with type 2 diabetes mellitus and microalbuminuria: the Steno type 2 randomised study. Lancet. 1999;353(9153):617-622

23. Jesper FR, Knud Y, Elisabeth G, Poul E J, Hans H L, Ebbe E, et al, Cardiovascular Autonomic Neuropathy Is Associated With Macrovascular Risk Factors in Type 2 Diabetes: New Technology Used for Routine Large-Scale Screening Adds New Insight. J Diabetes Sci Technol. 2014;8(4): 874-880

24. Gupta S, Gupta N. The Prevalence of Cardiac Autonomic Neuropathy in Type 2 Diabetes Mellitus. JMSCR. 2017;5(7):2463539 .

25. Barthwal SP, Agarwal R, Khanna D, Kumar P. QTC prolongation in diabetes mellitus- an indicator of cardiac autonomic neuropathy. J App Pharm Int. 1997;(45):15-17.

26. Mathur CP, Gupta.QTC prolongation in diabetes mellitus-an indicator of cardiac autonomic neuropathy.JIM. 2006;7(2):130 162.

27. Pappachan J, Sebastian J, Bino B, Jayaprakash K, Vijayakumar $\mathrm{K}$, Sujatha $\mathrm{P}$, et al. Cardiac autonomic neuropathy in diabetes mellitus: prevalence, risk factors and utility of corrected QT interval in the ECG for its diagnosis. Postgrad Med J. 2008; 84(990):205-210.

28. Refaie W. Assessment of cardiac autonomic neuropathy in longstanding type 2 diabetic women. EHJ. 2014; 66(1): 63-69.

29. Sukla P, Shrivastava SR, Shrivastava P S, Rao NL. Assessment of the cardiac autonomic neuropathy among the known diabetics and age-matched controls using non-invasive cardiovascular 
reflex tests in a South-Indian population: A case-control study. Avicenna J Med. 2016; 6(3): 81-85.

30. Haji KK, Shuaib A, Imran AS, Fatima Q. Cardiac AutonomicNeuropathy in Type-1 Diabetes Mellitus Patients and its Association with the duration of Disease and Glycemic Control. J Coll Physicians Surg Pak. 2009; 19(4): 232-235.

31. Ahire C, Sarode V, Jadhav K, Shreeram V, Gaidhani N. Prevalence of cardiac autonomic neuropathy in short and long-standing type 2 diabetics in western Maharashtra. Int J Basic Appl Med Res. 2014;3(4):252-259.

32. David CL, Henri KP, Gregg M and Aaron IV. 2012. Cardiac Autonomic Imbalance in Newly Diagnosed and Established Diabetes Is Associated with Markers of Adipose Tissue Inflammation. Exp. Diabetes Res.2012;2012:878760.

33. .Anca Moususianu, RodicaBslaGa, SeptimiuVoidszan, and ZoltánBajkó. Cardiovascular Autonomic Neuropathy in Context of Other Complications of Type 2 Diabetes Mellitus. Bio-Med Research International. 2013; 2013: 1-8.
34. .R. H. Straub, M. Thum, C. Hollerbach, K. D. Palitzsch, and J. Schölmerich. Impact of obesity on neuropathic late complications in NIDDM. Diacare. 1994; 17(11): 1290-1294.

35. B. Bergstrom, B. Lilja, S. Osterlin, and G. Sundkvist. Autonomic neuropathy in non-insulin-dependent (type II) diabetes mellitus. The possible influence of obesity, JIM.1990;227(1): 57-63.

36. Vincenza Spallone M Rosaria, Elina cicconetti,Guido Menzinger. Autonomic neuropathy and cardiovascular risk factors insulin dependent and non-insulin dependent diabetes. Diabetes Res Clin Pract.1997:34(3): 169-179.

37. Iris Shai, Rui Jiang, Joann E Manson, Meir J Stampfer, Walter C Willett, Graham A Colditz, et al. Ethnicity, obesity, and risk of type 2 diabetes in women: a 20 -year follow-up study. Deathcare. 2006; 29(7):1585-1590. 